\title{
Gestão de custos e despesas e a estratégia competitiva de diferenciação: setor autopeças
}

\section{Costs and expenses management strategy and competitive differentiation: automotive sector}

Viviane Chunques Gervasoni ${ }^{[a]}$, George Bedinelli Rossi ${ }^{[b]}$, Dirceu Silva ${ }^{[c]}$

[a] Mestre em Administração pela Universidade Nove de Julho (UNINOVE), São Paulo, SP - Brasil, e-mail: viviane.gervasoni@uol.com.br

[b] Doutor em Administração pela Escola Superior de Propaganda e Marketing (ESPM), São Paulo, SP - Brasil, e-mail: george.rossi@gmail.com

[c] Doutor em Educação pela Universidade Nove de Julho (UNINOVE), São Paulo, SP - Brasil, e-mail: dirceuds@gmail.com

\section{Resumo}

O objetivo desta pesquisa é investigar o quanto custos e despesas explicam a rentabilidade da empresa com ênfase na Estratégia Genérica de Diferenciação em Qualidade de Produto. A revisão da literatura indica que a rentabilidade da empresa depende da estratégia genérica adotada por esta para lidar com as forças estruturais da indústria. Dentre estas estratégias, a de diferenciação deve enfocar características únicas e valoradas pelos compradores e, ao mesmo tempo, atentar aos custos. Assim, este estudo foi feito usando os valores dos custos, despesas, patrimônio líquido e vendas de sete empresas, extraídos originalmente de demonstrativos contábeis divulgados pela BM\&F BOVESPA. Usou-se como critério de escolha da amostra das empresas uma seleção não probabilística e por julgamento, pois as seleções das empresas aqui estudadas têm capital aberto e sendo assim divulgam seus dados contábeis. Trata-se de uma pesquisa descritiva e explicativa quanto ao seu objetivo; multicaso e expost-facto quanto à estratégia de abordagem do problema, bibliográfica e documental quanto aos procedimentos técnicos de coleta de dados e quantitativa quanto à análise de dados. Os resultados, obtidos por meio de Regressão Múltipla $(\mathrm{R} 2=0,98)$, apontam que a rentabilidade do setor pode ser explicada pela estratégia genérica de diferenciação em qualidade do produto. Assim, a contribuição científica desta pesquisa é atestar que o dimensionamento dos custos, como exposto por Porter, é necessário para explicar a rentabilidade quando adotada a estratégia genérica de diferenciação em qualidade do produto no setor de autopeças.

Palavras-chave: Estratégia de diferenciação. Custo. Rentabilidade.

\section{Abstract}

The objective of this research is to investigate the costs and expenses and explain the company's profitability with an emphasis on generic strategies of differentiation in product quality. The literature indicates that the company's profitability depends on the generic strategy adopted to deal with these structural forces in the industry. Among these strategies, differentiation should focus on unique and valued by both buyers and pay attention to costs. Thus, this 
study was done using the values of the costs, expenses, net worth and sales of seven companies, originally extracted from financial statements published by BM\&F BOVESPA. It was used as the criterion for choosing a sample of companies and non-probability selection trial for the selections of the companies studied here are publicly traded and thus disclose their accounting data. It is a descriptive explanation as to its purpose; multicase and ex post facto on the approach to the problem, literature and public documents regarding the technical procedures for data collection, and quantitative and data analysis. The results obtained by means of multiple regression $(R 2=0.98)$ indicate that the profitability of the sector can be explained by the generic strategy of differentiation in product quality. Thus, the scientific contribution of this research is to certify that the design costs as discussed by Porter is necessary to explain the profitability when adopted the generic strategy of differentiation in product quality in the parts sector.

Keywords: Multilevel research. Practices. Organizations.

\section{Introdução}

Porter (1989) diz que o valor dos custos de uma empresa tem importantes implicações para o sucesso da estratégia diferenciação. Se a liderança em custos frente à diferenciação visar qualidade ou custo, o mercado tenderá a comprar o que apresentar o menor custo.

Para o setor de autopeças a maneira mais usual de mensurar a qualidade dá-se por meio das certificações que têm por objetivo garantir o estabelecimento de critérios padrões entre as relações de clientes e fornecedores (LAMENZA, 2008).

0 problema desta pesquisa surgiu baseado na ideia de Porter (2004) de que para o uso da estratégia de diferenciação, os custos e despesas devem ser dimensionados, para explicar a rentabilidade. Conforme Martins (2003), despesas são bens ou serviços consumidos direta ou indiretamente para a obtenção de receita, assim o objetivo desta pesquisa é investigar a importância relativa de custos e despesas para explicar a rentabilidade da empresa que adota a estratégia genérica diferenciação em qualidade de produto do setor de autopeças. Portanto, a hipótese desta pesquisa é: custos e despesas explicam a rentabilidade no setor de autopeças quando adotada a estratégia genérica de diferenciação em qualidade do produto.

Este estudo foi feito usando os valores dos custos, despesas, patrimônio líquido e vendas de sete empresas do setor de autopeças brasileiro, extraídos originalmente dos demonstrativos contábeis das mesmas, divulgados pela BM\&F BOVESPA. A coleta de dados foi exploratória, tipo documental (MALHOTRA, 2001). Foram calculados os seguintes valores: representatividade dos custos em relação às vendas, representatividade das despesas em relação às vendas, representatividade do patrimônio líquido em relação às vendas e rentabilidade de uma amostra de sete empresas do setor de autopeças. As empresas estudadas foram: Fras-Le S.A.; Iochpe Maxion S.A.; Mahle-Metal Leve S.A.; Marcopolo S.A.; Randon S.A. Implementos e Participações; Tupy S.A. e Metalúrgica Riosulense S.A.

Aplicou-se a análise de regressão, na qual a variável dependente estudada foi o valor da rentabilidade e as variáveis independentes foram os valores da representatividade dos custos em relação às vendas, representatividade das despesas em relação às vendas e representatividade do patrimônio líquido em relação às vendas.

\section{Suporte teórico-empírico}

O setor de autopeças, responsável pela produção, fornecimento e reposição de peças de veículos, está diretamente relacionado com as montadoras de veículos, tanto leves quanto pesados, máquinas agrícolas (ANFAVEA, 2009).

Para atingir competitividade neste mercado, as empresas estão direcionando uma maior atenção à tecnologia, reduções de custos e qualidade do produto, aperfeiçoando a produção e eliminando desperdícios. Evidências desta atenção à tecnologia podem ser observadas pelos investimentos feitos pelas empresas em Centros de Tecnologia, para aperfeiçoamento dos produtos desenvolvidos (CONSOLI; PEREIRA; REBELATTO, 2001).

Segundo Porter (2004), a estratégia de diferenciação do produto ou serviço baseia-se em alguns quesitos, tais como a produção de algo único em toda a 
indústria, o desenvolvimento da tecnologia empregada na fabricação dos produtos, assim como a qualidade do produto final. Esta diferenciação faz com que os consumidores tornem-se fiéis ao produto e à marca, afastando empresas e produtos rivais.

Porém, de acordo com Consoli, Pereira e Rebelatto (2001), para garantir esta diferenciação e ainda obter lucratividade, estas empresas devem:

a) manter custos baixos e garantir a qualidade do produto;

b) ser capazes de desenvolver e atualizar seus sistemas, de modo a evitar imitações e produtos rivais;

c) ser capazes de desenvolver projetos, com velocidade, atendendo às demandas das montadoras;

d) valorizar os recursos humanos, com melhores salários e qualificação da mão de obra;

e) aperfeiçoar os métodos administrativos adotados pela empresa;

f) repensar e investir na logística da empresa, englobando desde a entrada da matéria-prima até a entrega do produto final.

Atingir a diferenciação, atendendo os requisitos acima, torna-se um risco para as empresas, uma vez que os consumidores fiéis buscam menor preço e o volume de compras pode diminuir de acordo com a sofisticação dos compradores, com a imitação do produto ou mesmo a concorrência (PORTER, 2004). Mas é importante também tornar os custos de diferenciação uma vantagem competitiva, já que quando se minimizam os custos objetiva-se aumentar as vendas e a rentabilidade da empresa. Assim, algumas atividades que devem ser incorporadas às empresas, visando à redução de custos, Shank (1993 apud CONSOLI; PEREIRA; REBELATTO, 2001), são:

a) análise da cadeia de valor: compreender o comportamento dos custos e das fontes de diferenciação desde a matéria-prima até o consumidor final;

b) análise do posicionamento estratégico: estabelecer um sistema de controle e planejamento, levando-se em consideração o ambiente externo e interno de cada organização;

c) análise dos direcionadores de custos: analisar o comportamento dos custos e suas interações, explicando suas variações nas atividades de valor.
Estas atividades têm por finalidade viabilizar, analisar e mensurar, dentro de uma organização, as cinco forças propostas por Porter (1989), de forma a proporcionar a Gestão Estratégica da empresa, com a diferenciação nos custos.

Aliada às cinco forças de Porter, a estratégia precisa avaliar sempre a ambiência externa (oportunidades e ameaças) e a ambiência interna (pontos fortes e pontos fracos). Cruzando as informações adquiridas é possível avaliar e reavaliar a estratégia existente, encontrar pontos que devem ser aprimorados e aqueles que devem ser intensificados (MINTZBERG, 1990).

Desta forma, torna-se imprescindível saber aproveitar bem os recursos existentes na empresa, sejam os ativos, capacidades, processos organizacionais, atributos da empresa, informações e conhecimentos que, quando controlados pelas empresas, lhes permitem compreender e colocar em ação a estratégia com o objetivo de aumentar a eficiência e eficácia, gerando redução de custos ou a vantagem competitiva sustentável (BARNEY, 1991).

Tendo em vista que o pilar da economia moderna é a alocação de recursos de maneira eficiente e eficaz, recursos estes que devem ser geridos pela mão visível, através dos gestores das organizações, alocando o mercado em função dos preços praticados, aumentando a concorrência (GOLDMAN; GORTON, 2000).

0 fato de se ter a estratégia de diferenciação em tecnologia como objetivo não é suficiente para garantir a rentabilidade das organizações estudadas, se os seus gestores não tiverem uma postura de "agente trabalhista" dentro deste cenário (GOLDMAN; GORTON, 2000). Assim, com as palavras de Drejer (2002), as empresas estudadas encontram-se na Escola Complexa de Gestão Estratégica e tendem a uma forte formação de redes.

Dentro de um contexto econômico pode-se dizer que as organizações estudadas não estão sob o conceito de mão invisível que regula o mercado, estando, portanto, dentro da teoria da mão visível, pois o mercado é o gerador de demanda para a produção dos bens e para a prestação de serviços (GOLDMAN; GORTON, 2000).

Segundo Coase (1937), as empresas e os mercados alocam recursos diferentes, por isso as empresas devem coordenar as atividades econômicas quando o mercado não é capaz de fazê-lo, essas atitudes devem ser tomadas pelos gestores. Porém, se ainda assim os custos estiverem muito altos, é interessante analisar as operações que são mais dispendiosas, incluindo o ativo, bem como 
o dispêndio dos fatores de produção, visando realocar os mesmos. Outro aspecto que as empresas não podem esquecer é que o capital está inserido em um contexto jurídico e, portanto, a empresa é uma pessoa diferente do indivíduo (ALCHIAN; DEMSETZ, 1972).

O conceito de qualidade para Garvin (1992) possui cinco definições principais, que são: a transcendente, a baseada no produto, a baseada no usuário, a baseada na produção e a baseada no valor. Quando se fala na definição de qualidade entende-se que signifique "excelência inata", e que as diferenças percebidas na mesma podem ser vistas em algum ingrediente ou atributo do produto. Para Garvin (1992), a qualidade baseada no usuário parte da premissa de que o mesmo produto para cada consumidor que possui diferentes desejos e necessidades será "escolhido" diante do melhor atendimento de suas preferências. Já conceito da qualidade baseada na produção refere-se à conformidade do produto diante das especificações. Uma vez estabelecido um projeto ou uma especificação, qualquer desvio implica em uma queda da qualidade.

Segundo Garvin (1992), as categorias da qualidade como esquemas de análise são: desempenho, características, confiabilidade, conformidade, durabilidade, atendimento, estética e qualidade percebida. 0 desempenho são as características operacionais do produto; as características são os adereços; a confiabilidade é a probabilidade de falhas do produto dentro de um determinado período; a conformidade está ligada ao grau em que as características operacionais do produto estão de acordo com os padrões preestabelecidos; a durabilidade refere-se ao prazo de utilização do produto antes de sua quebra ou possíveis reparos; o atendimento está ligado à rapidez, cortesia e facilidade de reparo do produto; a estética está ligada à visão do usuário, por isso é a mais subjetiva; por fim a qualidade percebida está relacionada a falta de informações sobre um produto ou os atributos de um serviço.

Garvin (1992) menciona que cada vez mais empresas têm chegado à conclusão de que a qualidade é uma ferramenta poderosa junto à concorrência, tanto para ampliar o mercado que atuam quanto para minimizar os custos, o que provoca maior rentabilidade frente à concorrência. Um exemplo de como a alta qualidade e baixos custos caminham juntos é a abordagem japonesa de produção, onde se percebe como resultado de tal estratégia maiores quotas de mercado e maior rentabilidade (NARASIMHAN; GHOSH; MENDEZ, 1993).

Para Narasimhan, Ghosh e Mendez (1993), quando se pensava em qualidade no passado, indicava-se que havia a necessidade de novas tecnologias e, portanto, a necessidade de mais matéria-prima para a produção e, consequentemente, os custos de fabricação ficariam elevados em função dos altos investimentos que se fariam necessários. Se este ponto de vista fosse válido seria difícil para uma empresa exercer simultaneamente elevados níveis de qualidade para seus produtos com baixos custos.

Estudos realizados mostraram que esta ideia é desacreditada, pois conforme Narasimhan, Ghosh e Mendez (1993), a qualidade e os custos são compatíveis para a liderança em estratégias empresariais; sendo assim, os custos devem realmente diminuir mais rapidamente com a aquisição de maior experiência em se produzir produtos de alta qualidade.

Narasimhan, Ghosh e Mendez (1993) dizem que a qualidade dos produtos é hoje considerada um fator determinante para a maior parte da demanda de bens duráveis. Por conseguinte, uma estratégia de diferenciação através da qualidade superior dos produtos é uma forma eficaz e eficiente de aumentar a fidelização dos clientes e diminuir a sensibilidade dos preços, provocando redução dos custos e, portanto, aumento na rentabilidade.

Por fim, a qualidade baseada no valor usa a definição baseada em termos de custo e preço. Assim, um produto de qualidade é um produto que oferece um desempenho ou conformidade a um preço e a um custo aceitável. Porém, conforme Narasimhan, Ghosh e Mendez (1993), é a percepção da qualidade do cliente que é a mais importante, e que por isso deve ser levada em consideração.

Segundo Oliveira (2004), a qualidade dentro da gestão estratégica deve ser definida diante de padrões fixos e internos, são os clientes que determinam a aceitação de um produto, é a necessidade dos clientes que precisa ser atendida.

Conforme Lamenza (2008), a definição de qualidade passou por uma série de aprimoramentos; no início a preocupação era apenas com a qualidade do produto, a evolução deste conceito passou a associar-se ao controle do processo, à garantia e atualmente à qualidade estratégica. Nos dias atuais, o quesito da qualidade, segundo Lamenza (2008), não pode se restringir a uma área ou departamento, ela deve ser abordada por todos na empresa, de forma sistematizada. Se necessário, deve ser formalizada para que os procedimentos sejam mantidos e melhorados.

No setor de autopeças, para que uma empresa se qualifique como fornecedor de uma montadora é 
necessário a aquisição dos programas de certificação quanto a seus métodos de produção, controle de qualidade e capacidade de produção; a percepção da qualidade é verificada através das certificações. 0 objetivo das certificações é garantir os critérios padrões de qualidade para as relações de clientes e fornecedores, em um processo de compra e venda (LAMENZA, 2008).

Nesta pesquisa usaremos a premissa da qualidade baseada no produto, onde a mesma será mensurada como variável precisa, utilizando as informações disponíveis nos sites das empresas, e a baseada em valor mensurando o valor dos custos, usando as informações publicadas no site da BM\&F BOVESPA (2009), através dos demonstrativos contábeis das empresas do setor de autopeças, com capital aberto (S.A.).

Abaixo estão as características das empresas do setor de autopeças inseridas na BM\&F BOVESPA, apresentando a informação que evidencia a estratégia de diferenciação do produto via qualidade. Estas evidências são apresentadas a seguir.

Fras-Le S.A.

Fundada em 1954, a Fras-Le tem como atividade a produção de materiais de fricção. Seu negócio Segurança no Controle de Movimentos faz dela a maior empresa da América Latina e uma das líderes mundiais. No avançado Centro de Pesquisa e Desenvolvimento, um dos mais bem equipados do mundo, a Fras-Le S.A. conta com laboratórios químico, físico e piloto, que possibilita a geração de produtos com alto desempenho.

A Fras-Le foi o primeiro fabricante de materiais de fricção do Brasil a obter a certificação pela Norma ISO 9001, em 1995. Ela recebeu a certificação em 1999 pela Norma ISO 14001 e, em março de 2004, conquistou a recertificação da ISO 9001 na versão 2000. Em maio do mesmo ano conquistou a certificação da ISO/TS16949, sendo a primeira empresa fabricante de material de fricção a obter essa certificação (Fras-le, 2009).

\section{Mahle Metal Leve S.A.}

Desde 1950 no Brasil, a Mahle transformou-se em um modelo empresarial que conseguiu se destacar em um mercado altamente competitivo, concentrando esforços em tecnologia da qualidade e na formação de recursos humanos, contando com a participação real e efetiva de uma sólida estrutura financeira.
A empresa, hoje, é símbolo de qualidade em seus produtos, serviços e atendimento, sendo certificada pelas normas ISO/TS 16949, ISO 9001, ISO $14001 \mathrm{e}$ OHSAS 18001.

Em Jundiaí, o Laboratório da Mahle Powertrain Brasil iniciou atividades em 2006, atuando em vendas de Serviços de Engenharia na Calibração de Motores e Veículos, Emissões, Simulações Numéricas, Sistemas de Testes, Ruído e Vibrações. Há um laboratório de emissões gasosas de motores leves e pesados (Otto e Diesel), além de uma câmara semianecoica climatizada para análises de NVH. Esse Centro conta com uma equipe de 240 colaboradores, incluindo pesquisadores, engenheiros e técnicos atuando nas áreas de Pesquisa e Desenvolvimento, Vendas e Serviços de Engenharia (MAHLE, 2009).

\section{Marcopolo S.A.}

A Marcopolo foi fundada em 1949, em Caxias do Sul, Rio Grande do Sul, com o nome de Nicola \& Cia. Ltda. Em 1971, graças ao sucesso alcançado com o lançamento do ônibus "Marcopolo", passou a denominar-se Marcopolo S.A. O crescimento contínuo consolidou a organização, que já produziu em suas fábricas no Brasil e exterior, nestes 60 anos, 200.000 ônibus, com uma força de trabalho atual de mais de 12.000 colaboradores. A Marcopolo hoje se destaca no mercado nacional de ônibus e microônibus, além de manter uma constante presença no mercado internacional.

Dentre as certificações que possui está a ISO 9001, que é uma Norma Internacional que define os padrões mínimos para gerenciar o Sistema da Qualidade da empresa. Ela orienta as ações da empresa com foco nos processos necessários para satisfação do cliente em relação aos serviços e produtos fornecidos. Também possui a OHSAS 18001, uma Norma que orienta como a empresa deve ser gerenciada para que seus colaboradores tenham ambientes e condições seguras de trabalho. E também a SA 8000, norma SA instituída em 1997 pela organização americana Social Accountability International (MARCOPOLO, 2009).

\section{lochpe Maxion S.A.}

A Iochpe Maxion é uma empresa que detém a liderança em seus vários setores de atuação, na fabricação de chassis, rodas rodoviárias, vagões ferroviários 
e fundidos ferroviários. Dentre a variedade de segmentos industriais, destacamos os de chassis e rodas rodoviárias pela presença no competitivo mercado das autopeças, mantendo-se na posição de liderança.

Em Cruzeiro, a Divisão Rodas e Chassis da Maxion Sistemas Automotivos estão certificadas pela norma ISO 14001, que garante o comprometimento da empresa com métodos operacionais ambientalmente responsáveis e com a adoção de processos de tratamento e eliminação de resíduos alinhados aos mais elevados padrões de exigência.

\section{Randon S.A. Implementos e Participações}

A Randon chega aos 60 anos mantendo a liderança no mercado nacional como maior fabricante da América Latina e entre os 10 maiores fabricantes de implementos rodoviários do mundo. Tem mais de 250 mil produtos em operação e exporta para cerca de 70 países.

Suas certificações de qualidade incluem: ISO 9001; Fras-Le 1995; Freios Master 1996; Randon Veículos 1996; Randon Implementos 1998; Jost Brasil 1998; ISO 9002; Randon Consórcios; Freios Master 1996; FrasLe 1998; QS 9000; Freios Master 1996; Fras-Le 1998; ISO TS 16949; Fras-Le; Suspensys; OHSAS 18001; Jost Brasil; Suspensys; Freios Master - Distinção Q1 Ford; Suspensys - SA 8000 (RANDON, 2009).

\section{Metalúrgica Riosulense S.A.}

No mercado desde 1946, a Metalúrgica Riosulense S.A., ao longo dos anos, atingiu o status de maior fabricante latino-americano de guias, sedes e tuchos mecânicos de válvula, fundidos em ligas especiais. Foi com sua filosofia de qualidade que conquistou a certificação na Norma ISO/TS 16949:2002, alcançando assim o reconhecimento mundial (RIOSULENSE, 2009). Em 1997 iniciou o processo de adequação de seu sistema de asseguramento da qualidade à norma ISO 9002, concluído com a obtenção da certificação em março de 1999. Após esta etapa, esforços complementares foram dirigidos para adequação deste sistema aos requisitos QS-9000, norma pela qual a empresa se certificou em junho de 2001. Atualmente está estruturada para melhor atender aos requisitos da ISO/TS 16949:2002, certificada em março de 2004 e recertificada em abril de 2007 (RIOSULENSE, 2009).
Tupy S.A.

Fundada em 1938, em Joinville, Santa Catarina, região Sul do Brasil, a TUPY tem capacidade para produzir 500 mil toneladas anuais de peças em ferro fundido, em dois parques fabris: um em Joinville e outro em Mauá, no Estado de São Paulo, região Sudeste do Brasil. Estar entre as maiores e mais destacadas fundições do mundo é uma condição que a TUPY atribui à excelência de seus profissionais. Muitos deles das áreas de Engenharia de Desenvolvimento de Produtos, Engenharia Metalúrgica e Engenharia da Qualidade (TUPY, 2009). Dentre suas certificações, destacam-se: ISO 9000, ISO/TS 16949, ISO 14001, QS-9000.

\section{Metodologia}

O diferencial metodológico desta pesquisa é evidenciar que o modelo proposto originalmente por Porter (2004), de que custos devem ser minimizados para se ter sucesso na prática da estratégia de diferenciação, ocorre no Brasil para o setor de autopeças.

Usou-se como critério de escolha da amostra das empresas uma seleção não probabilística e por julgamento, pois as seleções das empresas aqui estudadas têm capital aberto e sendo assim divulgam seus dados contábeis. Trata-se de uma pesquisa descritiva e explicativa quanto ao seu objetivo; multicaso e expost-facto quanto à estratégia de abordagem do problema, bibliográfica e documental quanto aos procedimentos técnicos de coleta de dados e quantitativa quanto à análise de dados (MALHOTRA, 2001).

Uma vez que a estratégia de diferenciação, focando a qualidade do produto, deve dimensionar os custos (PORTER, 2004), foram pesquisadas empresas listadas na BM\&F BOVESPA (2009) do setor de autopeças, no período de 2000 a 2007, para a coleta de dados referentes a esses custos.

Os dados considerados para a análise foram: custos, despesas, patrimônio líquido e vendas das empresas, extraídos originalmente dos demonstrativos contábeis das mesmas, divulgados pela BM\&F BOVESPA. As Tabelas 1 a 7 apresentam os seguintes cálculos: representatividade dos custos em relação às vendas, representatividade das despesas em relação às vendas, representatividade do patrimônio líquido em relação às vendas, ou seja, o quanto cada empresa consegue vender em relação ao capital investido pelos sócios, patrimônio líquido; e a 
rentabilidade dos anos de 2000 a 2007. Os valores dos custos, vendas e patrimônio líquido foram divididos pelo valor de vendas do respectivo ano e seu resultado multiplicado por 100 para se obter o valor percentual da representatividade de cada um.

Os dados coletados, custos e despesas, dentre outros, estão expressos em milhares de reais. As empresas analisadas foram: Fras-Le S.A.; Iochpe Maxion S.A.; Mahle-Metal Leve S.A.; Marcopolo S.A.; Randon S.A. Implementos e Participações; Tupy S.A. e Metalúrgica Riosulense S.A. As empresas DHB Indústrias e Comércio S.A.; Indústrias Arteb S.A.; Recrusul S.A.; Wetzel S.A.; Plascar Participações Industriais S.A. e Wiest S.A. foram excluídas do estudo por falta de informações e também por apresentarem prejuízo dentro do período de 2000 a 2007.

Entende-se por vendas ou receita a entrada de elementos para o ativo (direitos da organização), sob a forma de dinheiro ou direitos a receber, correspondente, normalmente, à venda de mercadorias, de produtos ou à prestação de serviços (IUDÍCIBUS et al., 1998).

Os custos são os gastos relativos a bens ou serviços utilizados na produção de outros bens ou serviços (MARTINS, 2003). Já as despesas, conforme Martins (2003), são bens ou serviços consumidos direta ou indiretamente para a obtenção de receitas.
Como Patrimônio Líquido entende-se a diferença entre o valor de ativo (direitos) e do passivo (obrigações) de uma empresa, em um determinado momento (IUDÍCIBUS et al., 1998). Para se chegar ao valor de representatividade dos custos, dividiu-se o valor dos custos pelo valor das vendas de cada ano da série de 2000 a 2007, o mesmo foi feito com os valores das vendas, despesas e patrimônio líquido. Já a rentabilidade é mencionada como o índice ROE (ou return on equity), taxa de retorno sobre o patrimônio líquido, que conforme Kassai, Kassai e Santos (2000) é obtido por meio da fórmula: lucro líquido dividido pelo patrimônio líquido.

Ainda segundo Gitman (2004), rentabilidade ou ROE, retorno do capital próprio mede o retorno obtido no investimento do capital dos acionistas da empresa. Quanto maior for este número, melhor para os proprietários.

\section{Dados dos demonstrativos contábeis e calculados}

Os dados obtidos a partir dos demonstrativos contábeis e as respectivas representatividades calculadas foram (BM\&F BOVESPA, 2009):

Tabela 1 - Dados brutos e calculados Fras-Le S.A. 2000 a 2007

FRAS-LE S.A.

$R \$ 1.000$

\begin{tabular}{|c|c|c|c|c|c|c|c|c|c|}
\hline Ano & $\begin{array}{c}\text { Vendas } \\
\text { (R\$) }\end{array}$ & $\begin{array}{c}\text { Custos } \\
\text { (R\$) }\end{array}$ & $\begin{array}{l}\text { Representa- } \\
\text { tividade } \\
\text { dos custos } \\
(\%)\end{array}$ & $\begin{array}{c}\text { Despesas } \\
\text { (R\$) }\end{array}$ & $\begin{array}{l}\text { Represen- } \\
\text { tatividade } \\
\text { das despe- } \\
\text { sas }(\%)\end{array}$ & $\begin{array}{l}\text { Patrimônio } \\
\text { líquido } \\
\text { (R\$) }\end{array}$ & $\begin{array}{l}\text { Representa- } \\
\text { tividade do } \\
\text { patrimônio } \\
\text { líquido em } \\
\text { relação às } \\
\text { vendas (\%) }\end{array}$ & $\begin{array}{c}\text { Lucro } \\
\text { operacional } \\
\text { (R\$) }\end{array}$ & $\begin{array}{l}\text { Rentabi- } \\
\text { lidade (\%) }\end{array}$ \\
\hline 2000 & 173.263 & 115.047 & $66,40 \%$ & 43.474 & $25,09 \%$ & 66.264 & $38,24 \%$ & 14.742 & $22,25 \%$ \\
\hline 2001 & 180.731 & 115.507 & $63,91 \%$ & 53.590 & $29,65 \%$ & 71.079 & $39,33 \%$ & 11.634 & $16,37 \%$ \\
\hline 2002 & 221.987 & 135.614 & $61,09 \%$ & 66.908 & $30,14 \%$ & 74.282 & $33,46 \%$ & 19.465 & $26,20 \%$ \\
\hline 2003 & 274.477 & 174.263 & $63,49 \%$ & 68.235 & $24,86 \%$ & 89.066 & $32,45 \%$ & 31.979 & $35,90 \%$ \\
\hline 2004 & 375.030 & 225.070 & $60,01 \%$ & 111.932 & $29,85 \%$ & 114.918 & $30,64 \%$ & 38.028 & $33,09 \%$ \\
\hline 2005 & 373.643 & 252.857 & $67,67 \%$ & 87.444 & $23,40 \%$ & 136.954 & $36,65 \%$ & 33.342 & $24,35 \%$ \\
\hline 2006 & 391.550 & 265.190 & $67,73 \%$ & 85.578 & $21,86 \%$ & 164.263 & $41,95 \%$ & 40.782 & $24,83 \%$ \\
\hline 2007 & 419.911 & 290.964 & $69,29 \%$ & 87.941 & $20,94 \%$ & 191.790 & $45,67 \%$ & 41.006 & $21,38 \%$ \\
\hline
\end{tabular}

Fonte: Dados da pesquisa. 
Percebe-se no caso da empresa Fras-Le que aparentemente despesas tiveram aumento maior em relação à rentabilidade do período. Porém, custos tiveram aumento representativamente maiores (Tabela 2).

Para a empresa Iochpe-Maxion, os valores de custos tiveram aparente crescimento, em contrapartida, despesas cresceram menos, assim como a rentabilidade, chegando nos anos de 2002 e 2003 a apresentar valores negativos (Tabela 3 ).

No caso da empresa Mahle-Metal Leve, custos aumentaram mais que o dobro em relação à rentabilidade. Já as despesas mantiveram-se com aumentos pouco representativos (Tabela 4).
A empresa Marcopolo teve custos aumentados, despesas mantidas sem muitas alterações, e sua rentabilidade manteve-se sem consideráveis alterações (Tabela 5).

Os custos da empresa Randon aumentaram, porém as despesas foram reduzidas. A rentabilidade nos anos de 2005, 2006 e 2007 também foram reduzidas (Tabela 6).

A rentabilidade da empresa Tupy nos anos de 2002 e 2005 apresentam valores negativos consideráveis, os custos aumentaram mais que proporcionalmente em relação à redução das despesas, porém a rentabilidade ainda é reduzida (Tabela 7).

Tabela 2 - Dados brutos e calculados lochpe-Maxion S.A. 2000 a 2007

IOCHPE-MAXION S.A.

$\mathrm{R} \$ 1.000$

\begin{tabular}{cccccccccc}
\hline Ano & $\begin{array}{c}\text { Vendas } \\
\text { (R\$) }\end{array}$ & Custos (R\$) & $\begin{array}{c}\text { Representa- } \\
\text { tividade } \\
\text { dos custos } \\
(\%)\end{array}$ & $\begin{array}{c}\text { Despesas } \\
\text { (R\$) }\end{array}$ & $\begin{array}{c}\text { Represen- } \\
\text { tatividade } \\
\text { das despe- } \\
\text { sas (\%) }\end{array}$ & $\begin{array}{c}\text { Patrimônio } \\
\text { líquido } \\
\text { (R\$) }\end{array}$ & $\begin{array}{c}\text { Representa- } \\
\text { tividade do } \\
\text { patrimônio } \\
\text { líquido em } \\
\text { relação às } \\
\text { vendas (\%) }\end{array}$ & $\begin{array}{c}\text { Lucro } \\
\text { operacional } \\
\text { (R\$) }\end{array}$ & $\begin{array}{c}\text { Rentabi- } \\
\text { lidade (\%) }\end{array}$ \\
\hline 2000 & 623.975 & 508.263 & $81,46 \%$ & 102.120 & $16,37 \%$ & 167.389 & $26,83 \%$ & 13.592 & $8,12 \%$ \\
2001 & 373.705 & 293.596 & $78,56 \%$ & 55.383 & $14,82 \%$ & 181.801 & $48,65 \%$ & 24.726 & $13,60 \%$ \\
2002 & 411.224 & 324.614 & $78,94 \%$ & 110.845 & $26,95 \%$ & 156.636 & $38,09 \%$ & -24.235 & $-15,47 \%$ \\
2003 & 675.673 & 539.115 & $79,79 \%$ & 141.669 & $20,97 \%$ & 151.525 & $22,43 \%$ & -5.111 & $-3,37 \%$ \\
2004 & 1.098 .597 & 871.084 & $79,29 \%$ & 176.687 & $16,08 \%$ & 186.233 & $16,95 \%$ & 50.826 & $27,29 \%$ \\
2005 & 1.494 .029 & 1.205 .374 & $80,68 \%$ & 216.524 & $14,49 \%$ & 229.931 & $15,39 \%$ & 72.131 & $31,37 \%$ \\
2006 & 1.247 .574 & 1.028 .339 & $82,43 \%$ & 161.455 & $12,94 \%$ & 264.935 & $21,24 \%$ & 57.780 & $21,81 \%$ \\
\hline 2007 & 1.289 .282 & 1.053 .576 & $81,72 \%$ & 163.315 & $12,67 \%$ & 310.541 & $24,09 \%$ & 72.391 & $23,31 \%$ \\
\hline
\end{tabular}

Fonte: Dados da pesquisa.

Tabela 3 - Dados brutos e calculados Mahle-Metal leve S.A. 2000 a 2007

MAHLE-METAL LEVE S.A.

$\mathrm{R} \$ 1.000$

(continua)

\begin{tabular}{cccccccccc}
\hline Ano & $\begin{array}{c}\text { Vendas } \\
\text { (R\$) }\end{array}$ & Custos (R\$) & $\begin{array}{c}\text { Representa- } \\
\text { tividade } \\
\text { dos custos } \\
(\%)\end{array}$ & $\begin{array}{c}\text { Despesas } \\
\text { (R\$) }\end{array}$ & $\begin{array}{c}\text { Represen- } \\
\text { tatividade } \\
\text { das despe- } \\
\text { sas (\%) }\end{array}$ & $\begin{array}{c}\text { Patrimônio } \\
\text { líquido } \\
\text { (R\$) }\end{array}$ & $\begin{array}{c}\text { Representa- } \\
\text { tividade do } \\
\text { patrimônio } \\
\text { líquido em } \\
\text { relação às } \\
\text { vendas (\%) }\end{array}$ & $\begin{array}{c}\text { Lucro } \\
\text { operacional } \\
\text { (R\$) }\end{array}$ & $\begin{array}{c}\text { Rentabi- } \\
\text { lidade (\%) }\end{array}$ \\
\hline 2000 & 603.184 & 398.788 & $66,11 \%$ & 136.842 & $22,69 \%$ & 255.340 & $42,33 \%$ & 67.554 & $26,46 \%$ \\
2001 & 718.500 & 457.019 & $63,61 \%$ & 171.348 & $23,85 \%$ & 307.473 & $42,79 \%$ & 90.133 & $29,31 \%$ \\
2002 & 867.613 & 527.560 & $60,81 \%$ & 189.954 & $21,89 \%$ & 436.108 & $50,27 \%$ & 150.099 & $34,42 \%$ \\
\hline
\end{tabular}


Tabela 3 - Dados brutos e calculados Mahle-Metal leve S.A. 2000 a 2007

\begin{tabular}{cccccccccc}
\hline Ano & $\begin{array}{c}\text { Vendas } \\
\text { (R\$) }\end{array}$ & Custos (R\$) & $\begin{array}{c}\text { Representa- } \\
\text { tividade } \\
\text { dos custos } \\
(\%)\end{array}$ & $\begin{array}{c}\text { Despesas } \\
\text { (R\$) }\end{array}$ & $\begin{array}{c}\text { Represen- } \\
\text { tatividade } \\
\text { das despe- } \\
\text { sas (\%) }\end{array}$ & $\begin{array}{c}\text { Patrimônio } \\
\text { líquido } \\
\text { (R\$) }\end{array}$ & $\begin{array}{c}\text { Representa- } \\
\text { tividade do } \\
\text { patrimônio } \\
\text { líquido em } \\
\text { relação às } \\
\text { vendas (\%) }\end{array}$ & $\begin{array}{c}\text { Lucro } \\
\text { operacional } \\
\text { (R\$) }\end{array}$ & $\begin{array}{c}\text { Rentabi- } \\
\text { lidade (\%) }\end{array}$ \\
\hline 2003 & 1.189 .861 & 767.061 & $64,47 \%$ & 246.910 & $20,75 \%$ & 561.851 & $47,22 \%$ & 175.890 & $31,31 \%$ \\
2004 & 1.512 .327 & 1.006 .215 & $66,53 \%$ & 325.629 & $21,53 \%$ & 570.875 & $37,75 \%$ & 180.483 & $31,62 \%$ \\
2005 & 1.475 .307 & 1.121 .235 & $76,00 \%$ & 252.592 & $17,12 \%$ & 393.182 & $26,65 \%$ & 101.480 & $25,81 \%$ \\
2006 & 1.502 .961 & 1.124 .202 & $74,80 \%$ & 278.058 & $18,50 \%$ & 443.064 & $29,48 \%$ & 100.701 & $22,73 \%$ \\
2007 & 1.639 .357 & 1.207 .241 & $73,64 \%$ & 325.942 & $19,88 \%$ & 511.446 & $31,20 \%$ & 106.174 & $20,76 \%$ \\
\hline
\end{tabular}

Fonte: Dados da pesquisa.

Tabela 4 - Dados brutos e calculados Marcopolo S.A. 2000 a 2007

MARCOPOLO S.A.

$\mathrm{R} \$ 1.000$

\begin{tabular}{cccccccccc}
\hline Ano & $\begin{array}{c}\text { Vendas } \\
\text { (R\$) }\end{array}$ & Custos (R\$) & $\begin{array}{c}\text { Representa- } \\
\text { tividade } \\
\text { dos custos } \\
(\%)\end{array}$ & $\begin{array}{c}\text { Despesas } \\
\text { (R\$) }\end{array}$ & $\begin{array}{c}\text { Represen- } \\
\text { tatividade } \\
\text { das despe- } \\
\text { sas (\%) }\end{array}$ & $\begin{array}{c}\text { Patrimônio } \\
\text { líquido } \\
\text { (R\$) }\end{array}$ & $\begin{array}{c}\text { Representa- } \\
\text { tividade do } \\
\text { patrimônio } \\
\text { líquido em } \\
\text { relação às } \\
\text { vendas (\%) }\end{array}$ & $\begin{array}{c}\text { Lucro } \\
\text { operacional } \\
\text { (R\$) }\end{array}$ & $\begin{array}{c}\text { Rentabi- } \\
\text { lidade (\%) }\end{array}$ \\
\hline 2000 & 833.517 & 669.668 & $80,34 \%$ & 146.645 & $17,59 \%$ & 212.611 & $25,51 \%$ & 17.204 & $8,09 \%$ \\
2001 & 1.056 .557 & 794.902 & $75,24 \%$ & 221.516 & $20,97 \%$ & 212.271 & $20,09 \%$ & 40.139 & $18,91 \%$ \\
2002 & 1.481 .607 & 1.109 .386 & $74,88 \%$ & 318.412 & $21,49 \%$ & 340.183 & $22,96 \%$ & 53.809 & $15,82 \%$ \\
2003 & 1.288 .523 & 1.038 .703 & $80,61 \%$ & 168.884 & $13,11 \%$ & 381.113 & $29,58 \%$ & 80.936 & $21,24 \%$ \\
2004 & 1.605 .445 & 1.332 .010 & $82,97 \%$ & 188.413 & $11,74 \%$ & 427.927 & $26,65 \%$ & 85.022 & $19,87 \%$ \\
2005 & 1.709 .078 & 1.451 .842 & $84,95 \%$ & 174.835 & $10,23 \%$ & 464.110 & $27,16 \%$ & 82.401 & $17,75 \%$ \\
2006 & 1.750 .285 & 1.420 .545 & $81,16 \%$ & 208.899 & $11,94 \%$ & 535.981 & $30,62 \%$ & 120.841 & $22,55 \%$ \\
\hline 2007 & 2.129 .164 & 1.766 .616 & $82,97 \%$ & 230.253 & $10,81 \%$ & 592.548 & $27,83 \%$ & 132.295 & $22,33 \%$ \\
\hline
\end{tabular}

Fonte: Dados da pesquisa.

Tabela 5 - Dados brutos e calculados Randon S.A. Implementos e Participações 2000 a 2007 RANDON S.A. IMPLEMENTOS E PARTICIPAÇÕES

\begin{tabular}{cccccccccc}
\hline Ano & $\begin{array}{c}\text { Vendas } \\
\text { (R\$) }\end{array}$ & Custos (R\$) & $\begin{array}{c}\text { Representa- } \\
\text { tividade } \\
\text { dos custos } \\
(\%)\end{array}$ & $\begin{array}{c}\text { Despesas } \\
\text { (R\$) }\end{array}$ & $\begin{array}{c}\text { Represen- } \\
\text { tatividade } \\
\text { das despe- } \\
\text { sas (\%) }\end{array}$ & $\begin{array}{c}\text { Patrimônio } \\
\text { líquido } \\
\text { (R\$) }\end{array}$ & $\begin{array}{c}\text { Representa- } \\
\text { tividade do } \\
\text { patrimônio } \\
\text { líquido em } \\
\text { relação às } \\
\text { vendas (\%) }\end{array}$ & $\begin{array}{c}\text { Lucro } \\
\text { operacional } \\
\text { (R\$) }\end{array}$ & $\begin{array}{c}\text { Rentabi- } \\
\text { lidade (\%) }\end{array}$ \\
\hline 2000 & 612.794 & 431.924 & $70,48 \%$ & 183.108 & $29,88 \%$ & 113.133 & $18,46 \%$ & -2.238 & $-1,98 \%$ \\
2001 & 683.393 & 472.142 & $69,09 \%$ & 206.388 & $30,20 \%$ & 112.273 & $16,43 \%$ & 4.863 & $4,33 \%$ \\
\hline
\end{tabular}


Tabela 5 - Dados brutos e calculados Randon S.A. Implementos e Participações 2000 a 2007 RANDON S.A. IMPLEMENTOS E PARTICIPAÇÕES

$\mathrm{R} \$ 1.000$

(conclusão)

\begin{tabular}{ccccccccccc}
\hline Ano & $\begin{array}{c}\text { Vendas } \\
\text { (R\$) }\end{array}$ & Custos (R\$) & $\begin{array}{c}\text { Representa- } \\
\text { tividade } \\
\text { dos custos } \\
\text { (\%) }\end{array}$ & $\begin{array}{c}\text { Despesas } \\
\text { (R\$) }\end{array}$ & $\begin{array}{c}\text { Represen- } \\
\text { tatividade } \\
\text { das despe- } \\
\text { sas (\%) }\end{array}$ & $\begin{array}{c}\text { Patrimônio } \\
\text { líquido } \\
\text { (R\$) }\end{array}$ & $\begin{array}{c}\text { Representa- } \\
\text { tividade do } \\
\text { patrimônio } \\
\text { líquido em } \\
\text { relação às } \\
\text { vendas (\%) }\end{array}$ & $\begin{array}{c}\text { Lucro } \\
\text { operacional } \\
\text { (R\$) }\end{array}$ & $\begin{array}{c}\text { Rentabi- } \\
\text { lidade (\%) }\end{array}$ \\
\hline 2002 & 833.377 & 575.352 & $69,04 \%$ & 244.320 & $29,32 \%$ & 116.612 & $13,99 \%$ & 13.705 & $11,75 \%$ \\
2003 & 1.137 .037 & 811.049 & $71,33 \%$ & 255.842 & $22,50 \%$ & 167.368 & $14,72 \%$ & 70.146 & $41,91 \%$ \\
2004 & 1.636 .291 & 1.101 .704 & $67,33 \%$ & 409.708 & $25,04 \%$ & 253.996 & $15,52 \%$ & 124.879 & $49,17 \%$ \\
2005 & 1.936 .143 & 1.441 .165 & $74,43 \%$ & 376.490 & $19,45 \%$ & 334.839 & $17,29 \%$ & 118.488 & $35,39 \%$ \\
2006 & 2.021 .041 & 1.493 .894 & $73,92 \%$ & 393.764 & $19,48 \%$ & 525.690 & $26,01 \%$ & 133.383 & $25,37 \%$ \\
2007 & 2.530 .223 & 1.859 .111 & $73,48 \%$ & 497.753 & $19,67 \%$ & 622.944 & $24,62 \%$ & 173.359 & $27,83 \%$ \\
\hline
\end{tabular}

Fonte: Dados da pesquisa.

Tabela 6 - Dados brutos e calculados Tupy S.A. 2000 a 2007

TUPY S.A.

$\mathrm{R} \$ 1.000$

\begin{tabular}{cccccccccc}
\hline Ano & $\begin{array}{c}\text { Vendas } \\
\text { (R\$) }\end{array}$ & Custos (R\$) & $\begin{array}{c}\text { Representa- } \\
\text { tividade } \\
\text { dos custos } \\
\text { (\%) }\end{array}$ & $\begin{array}{c}\text { Despesas } \\
\text { (R\$) }\end{array}$ & $\begin{array}{c}\text { Represen- } \\
\text { tatividade } \\
\text { das despe- } \\
\text { sas (\%) }\end{array}$ & $\begin{array}{c}\text { Patrimônio } \\
\text { líquido } \\
\text { (R\$) }\end{array}$ & $\begin{array}{c}\text { Representa- } \\
\text { tividade do } \\
\text { patrimônio } \\
\text { líquido em } \\
\text { relação às } \\
\text { vendas (\%) }\end{array}$ & $\begin{array}{c}\text { Lucro } \\
\text { operacional } \\
\text { (R\$) }\end{array}$ & $\begin{array}{c}\text { Rentabi- } \\
\text { lidade (\%) }\end{array}$ \\
\hline 2000 & 516.320 & 376.033 & $72,83 \%$ & 122.787 & $23,78 \%$ & 165.412 & $32,04 \%$ & 17.500 & $10,58 \%$ \\
2001 & 578.218 & 411.047 & $71,09 \%$ & 147.822 & $25,57 \%$ & 179.985 & $31,13 \%$ & 19.349 & $10,75 \%$ \\
2002 & 833.702 & 560.535 & $67,23 \%$ & 325.622 & $39,06 \%$ & 127.530 & $15,30 \%$ & -52.455 & $-41,13 \%$ \\
2003 & 1.112 .461 & 836.656 & $75,21 \%$ & 266.732 & $23,98 \%$ & 135.615 & $12,19 \%$ & 9.073 & $6,69 \%$ \\
2004 & 1.467 .383 & 1.128 .240 & $76,89 \%$ & 324.227 & $22,10 \%$ & 155.722 & $10,61 \%$ & 14.916 & $9,58 \%$ \\
2005 & 1.674 .194 & 1.292 .545 & $77,20 \%$ & 511.649 & $30,56 \%$ & 222.880 & $13,31 \%$ & -130.000 & $-58,33 \%$ \\
2006 & 1.610 .428 & 1.256 .692 & $78,03 \%$ & 319.108 & $19,82 \%$ & 252.216 & $15,66 \%$ & 34.628 & $13,73 \%$ \\
2007 & 1.595 .765 & 1.284 .906 & $80,52 \%$ & 199.441 & $12,50 \%$ & 633.542 & $39,70 \%$ & 111.418 & $17,59 \%$ \\
\hline
\end{tabular}

Fonte: Dados da pesquisa.

Tabela 7 - Dados brutos e calculados Metalúrgica Riosulense S.A. 2000 a 2007

METALÚRGICA RIOSULENSE S.A.

$\mathrm{R} \$ 1.000$

(continua)

\begin{tabular}{lccccccccc}
\hline Ano & $\begin{array}{c}\text { Vendas } \\
\text { (R\$) }\end{array}$ & Custos (R\$) & $\begin{array}{c}\text { Representa- } \\
\text { tividade } \\
\text { dos custos } \\
(\%)\end{array}$ & $\begin{array}{c}\text { Despesas } \\
\text { (R\$) }\end{array}$ & $\begin{array}{c}\text { Represen- } \\
\text { tatividade } \\
\text { das despe- } \\
\text { sas (\%) }\end{array}$ & $\begin{array}{c}\text { Patrimônio } \\
\text { líquido } \\
\text { (R\$) }\end{array}$ & $\begin{array}{c}\text { Representa- } \\
\text { tividade do } \\
\text { patrimônio } \\
\text { líquido em } \\
\text { relação às } \\
\text { vendas (\%) }\end{array}$ & $\begin{array}{c}\text { Lucro } \\
\text { operacional } \\
\text { (R\$) }\end{array}$ & $\begin{array}{c}\text { Rentabi- } \\
\text { lidade (\%) }\end{array}$ \\
\hline 2000 & 18.756 & 11.154 & $59,47 \%$ & 7.471 & $39,83 \%$ & 4.062 & $21,66 \%$ & 131,00 & $3,23 \%$ \\
\hline
\end{tabular}


Tabela 7 - Dados brutos e calculados Metalúrgica Riosulense S.A. 2000 a 2007 METALÚRGICA RIOSULENSE S.A.

$\mathrm{R} \$ 1.000$

(conclusão)

\begin{tabular}{cccccccccc}
\hline Ano & $\begin{array}{c}\text { Vendas } \\
\text { (R\$) }\end{array}$ & Custos (R\$) & $\begin{array}{c}\text { Representa- } \\
\text { tividade } \\
\text { dos custos } \\
(\%)\end{array}$ & $\begin{array}{c}\text { Despesas } \\
\text { (R\$) }\end{array}$ & $\begin{array}{c}\text { Represen- } \\
\text { tatividade } \\
\text { das despe- } \\
\text { sas (\%) }\end{array}$ & $\begin{array}{c}\text { Patrimônio } \\
\text { líquido } \\
\text { (R\$) }\end{array}$ & $\begin{array}{c}\text { Representa- } \\
\text { tividade do } \\
\text { patrimônio } \\
\text { líquido em } \\
\text { relação às } \\
\text { vendas (\%) }\end{array}$ & $\begin{array}{c}\text { Lucro } \\
\text { operacional } \\
\text { (R\$) }\end{array}$ & $\begin{array}{c}\text { Rentabi- } \\
\text { lidade (\%) }\end{array}$ \\
\hline 2001 & 22.154 & 14.145 & $63,85 \%$ & 7.380 & $33,31 \%$ & 4.785 & $21,60 \%$ & 629,00 & $13,15 \%$ \\
2002 & 29.763 & 18.772 & $63,07 \%$ & 10.747 & $36,11 \%$ & 5.059 & $17,00 \%$ & 244,00 & $4,82 \%$ \\
2003 & 41.956 & 27.945 & $66,61 \%$ & 13.055 & $31,12 \%$ & 5.744 & $13,69 \%$ & 956,00 & $16,64 \%$ \\
2004 & 61.488 & 43.382 & $70,55 \%$ & 16.406 & $26,68 \%$ & 7.088 & $11,53 \%$ & $1.700,00$ & $23,98 \%$ \\
2005 & 76.491 & 53.609 & $70,09 \%$ & 20.947 & $27,38 \%$ & 8.592 & $11,23 \%$ & $1.935,00$ & $22,52 \%$ \\
2006 & 88.497 & 62.770 & $70,93 \%$ & 24.575 & $27,77 \%$ & 9.489 & $10,72 \%$ & $1.152,00$ & $12,14 \%$ \\
2007 & 107.022 & 77.711 & $72,61 \%$ & 25.918 & $24,22 \%$ & 12.057 & $11,27 \%$ & $3.393,00$ & $28,14 \%$ \\
\hline
\end{tabular}

Fonte: Dados da pesquisa.

0 aumento dos custos e a redução das despesas não proporcionaram maiores rentabilidades para a empresa Metalúrgica Riosulense.

\section{Análise dos resultados}

A partir dos dados obtidos nos demonstrativos contábeis das empresas e também com os dados calculados das respectivas representatividades de custos, despesas e patrimônio líquido frente às vendas, fez-se uso da regressão linear múltipla para cada uma das empresas a fim de quantificar a importância de custos sobre a rentabilidade para averiguar a proposição de Porter (2004), de que custos devem ser minimizados quando adotada a estratégia de diferenciação, qualidade de produto (GUERRA; DONAIRE, 1986).

A regressão linear foi elaborada da seguinte maneira: a variável dependente é a rentabilidade e as independentes são representatividades dos custos, despesas e patrimônio líquido frente às vendas.

A Tabela 8 apresenta os dados referentes à empresa Fras-Le S.A., obtidos pela regressão linear múltipla. A representatividade dos custos, representatividade das despesas e representatividade do patrimônio líquido frente às vendas explicam 99,52\% do valor da rentabilidade, conforme expresso pelo valor do R-Quadrado.

Para a empresa Iochpe-Maxion S.A. as representatividades dos custos, despesas e patrimônio líquido frente às vendas explicam 93,19\% do valor da rentabilidade,
Tabela 8 - Dados regressão Fras-Le S.A.

\begin{tabular}{lr}
\hline \multicolumn{2}{c}{ Estatística de regressão } \\
\hline R-múltiplo & 0,997640093 \\
R-quadrado & 0,995285756 \\
R-quadrado ajustado & 0,991750073 \\
Erro padrão & 0,005735319 \\
Observações & 8 \\
\hline
\end{tabular}

Fonte: Dados da pesquisa.

conforme expresso pelo valor do R-Quadrado, obtido pela regressão linear múltipla, conforme Tabela 9.

Já na empresa Mahle Metal Leve S.A., as representatividades dos custos, despesas e patrimônio líquido frente às vendas explicam 98,37\% do valor da rentabilidade, conforme expresso pelo valor do R-Quadrado, de acordo com a Tabela 10.

No resultado da Marcopolo S.A., as representatividades dos custos, despesas e patrimônio líquido frente às vendas explicam 99,97\% do valor da rentabilidade, conforme expresso pelo valor do R-Quadrado, obtido pela regressão linear múltipla, de acordo com a Tabela 11.

Na Randon S.A. Implementos e Participações, a representatividade dos custos, despesas e patrimônio líquido frente às vendas explica 99,15\% do valor da rentabilidade, conforme expresso pelo valor do R-Quadrado, constante na Tabela 12, aplicada a regressão linear múltipla. 
Para a Tupy S.A., a representatividade dos custos, despesas e patrimônio líquido frente às vendas explicam $99,73 \%$ do valor da rentabilidade, conforme expresso pelo valor do R-Quadrado, obtido pela regressão linear múltipla, de acordo com a Tabela 13.

No caso da empresa Metalúrgica Riosulense S.A., a representatividade dos custos, despesas e patrimônio líquido frente às vendas explica $96,22 \%$ do valor da rentabilidade, conforme expresso pelo valor do R-Quadrado obtido pela regressão linear, conforme Tabela 14.

Tabela 9 - Dados regressão lochpe-Maxion S.A.

\begin{tabular}{lr}
\hline \multicolumn{2}{c}{ Estatística de regressão } \\
\hline R múltiplo & 0,965327871 \\
R-Quadrado & 0,931857898 \\
R-quadrado ajustado & 0,880751322 \\
Erro padrão & 0,055799327 \\
Observações & 8 \\
\hline
\end{tabular}

Fonte: Dados da pesquisa.

$\sigma: p \leq 0,05$

Tabela 10 - Dados regressão Mahle Metal-Leve S.A.

\begin{tabular}{lc}
\hline \multicolumn{2}{c}{ Estatística de regressão } \\
\hline R múltiplo & 0,991839684 \\
R-Quadrado & 0,983745958 \\
R-quadrado ajustado & 0,971555427 \\
Erro padrão & 0,007910297 \\
Observações & 8 \\
\hline
\end{tabular}

Fonte: Dados da pesquisa.

$\sigma: p \leq 0,05$

Tabela 11 - Dados regressão Marcopolo S.A.

\begin{tabular}{lr}
\hline \multicolumn{2}{c}{ Estatística de regressão } \\
\hline R múltiplo & 0,999835303 \\
R-Quadrado & 0,999670633 \\
R-quadrado ajustado & 0,999423607 \\
Erro padrão & 0,001134675 \\
Observações & 8 \\
\hline
\end{tabular}

Fonte: Dados da pesquisa.

$\sigma: p \leq 0,05$
Tabela 12 - Dados regressão Randon S.A. Implementos e Participações

\begin{tabular}{lc}
\hline \multicolumn{2}{c}{ Estatística de regressão } \\
\hline R múltiplo & 0,995716977 \\
R-Quadrado & 0,991452298 \\
R-quadrado ajustado & 0,985041521 \\
Erro padrão & 0,022225726 \\
Observações & 8 \\
\hline
\end{tabular}

Fonte: Dados da pesquisa.

$\sigma: p \leq 0,05$

Tabela 13 - Dados regressão Tupy S.A.

\begin{tabular}{lr}
\hline \multicolumn{2}{c}{ Estatística de regressão } \\
\hline R múltiplo & 0,998657467 \\
R-Quadrado & 0,997316736 \\
R-quadrado ajustado & 0,995304288 \\
Erro padrão & 0,019791241 \\
Observações & 8 \\
\hline
\end{tabular}

Fonte: Dados da pesquisa.

$\sigma: p \leq 0,05$

Tabela 14 - Dados regressão Metalúrgica Riosulense S.A.

\begin{tabular}{lc}
\hline \multicolumn{2}{c}{ Estatística de regressão } \\
\hline R múltiplo & 0,980902394 \\
R-Quadrado & 0,962169506 \\
R-quadrado ajustado & 0,933796635 \\
Erro padrão & 0,023092418 \\
Observações & 8 \\
\hline
\end{tabular}

Fonte: Dados da pesquisa.

$\sigma: p \leq 0,05$

Assim, como é possível perceber pelo estudo das regressões realizadas, o dimensionamento dos custos, despesas e a relação do patrimônio líquido frente às vendas, quando adotada a estratégia de diferenciação na qualidade do produto, explica a rentabilidade das empresas em aproximadamente $98 \%$. 


\section{Conclusão}

Assim, a pergunta de pesquisa exposta neste trabalho, qual seja, o dimensionamento dos custos, despesas e a relação do patrimônio líquido frente às vendas quando adotada a estratégia de diferenciação na qualidade do produto explica a rentabilidade, foi exposto de maneira positiva e quantificado por meio dos resultados da pesquisa das regressões lineares múltiplas estatísticas.

Quanto ao objetivo desta pesquisa, as estimativas de parâmetros obtidos por meio dos resultados dos R2 fornecem fortes evidências de que quantificar o valor dos custos quando adotada a estratégia de diferenciação na qualidade do produto faz-se necessário, conforme Porter (2004).

A hipótese de que o dimensionamento dos custos, despesas e patrimônio líquido frente às vendas explicam a rentabilidade foi corroborada, evidenciados estimativas de parâmetros obtidos pelas regressões demonstradas.

Assim, concluiu-se que o dimensionamento dos custos, como exposto por Porter (2004), é necessário para explicar a rentabilidade das empresas aqui estudadas.

\section{Sugestões para pesquisas futuras e limitações deste estudo}

As limitações desta pesquisa são que a amostra foi específica ao setor de autopeças brasileiro e o número de empresas estudadas não permite generalizações.

Este estudo incentiva a pesquisa quanto ao volume de custos, despesas e relação entre patrimônio líquido e vendas ideais, frente à qualidade obtida através das certificações versus rentabilidade. Sugere-se que os modelos testados possam ser reaplicados a amostras, períodos e mesmo segmentos diferentes dos estudados neste artigo, aumentando o número amostral e diversificando segmentos. Esmiuçar os motivos pelo qual este setor ainda atem-se apenas aos processos de certificações para atingir a qualidade, visto que se trata de processos dispendiosos de tempo e de recursos financeiros e que nem sempre trazem a rentabilidade desejada.

Em relação ao aspecto profissional-acadêmico, este trabalho possibilitou um aprofundamento nas questões: estratégia diferenciação na qualidade do produto, custos, despesas, patrimônio líquido, certificações e qualidade, o que possibilita um entendimento maior sobre o cenário do setor de autopeças, podendo ser transmitido a todos que interessar.

\section{Referências}

ALCHIAN, A. A.; DEMSETZ, H. Production, information costs, and economic organization. The American Economic Review, v. 62, n. 5, p. 777-795, 1972. Disponível em: <http://web.cenet.org.cn/upfile/100413.pdf>. Acesso em: 5 jun. 2009.

ASSOCIAÇÃO NACIONAL DOS FABRICANTES DE VEÍ CULOS - ANFAVEA. Disponível em: <http://www.anfavea. com.br/50anos.html>. Acesso em: 5 maio 2009.

BARNEY, J. Firm resources and sustained competitive advantage. Journal of Management, v. 17, n. 1, p. 99-120, 1991.

BM\&F BOVESPA. Empresa para investidores. Disponível em: <http://www.bovespa.com.br/Empresas/InformacoesEmpresas/FormConsultaEmpresas.asp>. Acesso em: 27 maio 2009.

COASE, R. H. The nature of the firm. Economica, v. 4, n. 16, p. 386-405, 1937. Disponível em: <http://www.sonoma. edu/users/e/eyler/426/coase1.pdf>. Acesso em: 5 jun. 2009.

CONSOLI, M. V.; PEREIRA, F. S.; REBELATTO, D. A. N. A gestão estratégica de custos como ferramenta para gestão econômica e estratégica das empresas: o setor de autopeças nacional neste contexto. In: ENCONTRO NACIONAL DE ENGENHARIA DE PRODUÇÃO, 21., 2001, Salvador. Anais... Salvador: ENEGEP, 2001. Disponível em: <http://www. abepro.org.br/biblioteca/enegep2001_tr32_0766.pdf>. Acesso em: 4 jun. 2009.

DREJER, A. Strategic management and core competencies: theory and application. Westport: Quorum Books, 2002.

FRAS-LE. Fras-Le S.A. Disponível em: <http://www.fras-le. com/fras-le/>. Acesso em: 13 jun. 2009.

GARVIN, D. A. Gerenciando a qualidade: a visão estratégica e competitiva. Rio de Janeiro: Qualitymark, 1992.

GITMAN, L. J. Princípios de administração financeira. 10. ed. São Paulo: Pearson Addison Wesley, 2004.

GOLDMAN, E.; GORTON, G. The visible hand, the invisible hand and efficiency. National Bureau of Economic Research, Cambridge, n. 7587, 2000. Disponível em: <http://www.nber. org/papers/w7587>. Acesso em: 16 maio 2009. 
GUERRA, J. M.; DONAIRE, D. Estatística indutiva. 3. ed. São Paulo: Livraria Ciência e Tecnologia Editora, 1986.

IUDÍCIBUS, S. et al. Contabilidade introdutória. 9. ed. São Paulo: Atlas, 1998.

KASSAI, J. R.; KASSAI, S.; SANTOS, A. dos. Retorno de investimento: abordagem matemática e contábil do lucro empresarial. 2. ed. São Paulo: Atlas, 2000.

LAMENZA, A. Estratégias empresariais: pesquisas e casos brasileiros. São Paulo: Saint Paul, 2008.

MAHLE. Mahle-Metal Leve S.A. Disponível em: <http:// www.mahle.com.br/C12570C2003CB56C/vwContentByKey/W26FHNNG351MARSPT>. Acesso em: 13 jun. 2009.

MALHOTRA, N. K. Pesquisa de marketing: uma orientação aplicada. Porto Alegre: Bookman, 2001.

MARCOPOLO. Marcopolo S.A. Disponível em: <http:// www.marcopolo.com.br/website/marcopolo_pt/content/ marcopolo/marcopolo/>. Acesso em: 13 jun. 2009.

MARTINS, E. Contabilidade de custos. 9. ed. São Paulo: Atlas, 2003.

MINTZBERG, H. The design school: reconsidering the basic premises of strategic management. Strategic Management Journal, v. 11, n. 3, p. 171-195, 1990.
NARASIMHAN, R.; GHOSH, S.; MENDEZ, D. A dynamic model of product quality and pricing decisions on sales response. Decision Sciences, v. 24, n. 5, p. 893-908, 1993.

OLIVEIRA, O. J. Gestão da qualidade: tópicos avançados. 2. ed. São Paulo: Pioneira Thomson Learning, 2004.

PORTER, M. E. Vantagem competitiva: criando e sustentando um desempenho superior. 12. ed. Rio de Janeiro: Campus, 1989.

PORTER, M. E. Estratégia competitiva: técnicas para análise de indústrias e da concorrência. 2. ed. Rio de Janeiro: Campus, 2004.

RANDON. Randon S.A. Implementos e Participações. Disponível em: <http://www.randon.com.br>. Acesso em: 13 jun. 2009.

RIOSULENSE. Metalúrgica Riosulense S.A. Disponível em: <http://www.riosulense.com.br/pt/home/>. Acesso em: 13 jun. 2009.

TUPY. Tupy S.A. Disponível em: <http://www.tupy.com.br/ portugues/empresa/>. Acesso em: 13 jun. 2009.

Recebido: 20/06/2011

Received: 06/20/2011

Aprovado: $29 / 08 / 2011$

Approved: 08/29/2011 